\title{
The Direct Costs of type 2 Diabetes Mellitus Outpatient care in the Ghanaian Public Health System: A Case of the Cape Coast Teaching Hospital
}

\author{
Immanuel Amissah MD ${ }^{1}$, Joy Dzidzor Dunyah BSc ${ }^{2}$ \\ ${ }^{1}$ Department of Internal Medicine \& Therapeutics, University of Cape Coast School of Medical Sciences, Ghana \\ ${ }^{2}$ Department of Internal Medicine \& Therapeutics, University of Cape Coast School of Medical Sciences, Ghana
}

\begin{abstract}
Background: Diabetes Mellitus (DM) is a growing epidermic with its parallel economic impact on the health system and society. The objective of this study was to estimate the direct medical and direct non-medical costs of type 2 diabetes outpatient care in a Ghanaian Public Health Care System. Methods: The study was conducted at the Cape Coast Teaching Hospital outpatient diabetes clinic from January, 2016 through May, 2016. A total of 204 randomly selected patients with diabetes attending the diabetes clinic were interviewed and their medical records data reviewed. Direct medical costs included expenses with anti-diabetic medications, diabetesrelated laboratory tests, blood glucose strips and consultations with healthcare professional's. Direct non-medical costs included expenses with transportation, artificial sweeteners and herbal medicines. Results: The annual mean direct medical cost for outpatient care for a person with DM was 1,491.45 Ghana cedis (US\$ 390.43) on oral anti-diabetics paid by the National Health Insurance Scheme, out of which medications accounted for the largest proportion of the direct medical cost (42.7\%), followed by cost of glucose strips (16.6\%). Also, on the average a person with diabetes spend out of pocket of 188.29 GHS (US\$ 49.29) per year in private pharmacies for diabetes medications. Also longer duration of the disease was associated with increased cost and the mean annual direct medical cost was higher in females than males (US\$ $362.98 \mathrm{vs} \$ 332.58$ ). Having hypertension and dyslipidaemia as co-morbities added an additional cost of US\$123.02 and \$90.16 respectively on medications for treatment annually. The mean direct non-medical cost was GHS 110.93 (US\$ 29.04), out of which transportation accounted for the largest proportion (52.3\%).Conclusion:This study showed that outpatient diabetes management leads to elevated cost to the Ghanaian Public Health care System. Costs increased along with duration of disease and presence of co-morbities. There is the need to focus on primary prevention of diabetes, its co-morbidities and complications.
\end{abstract}

Keywords: Type 2 diabetes, direct medical costs, Ghana, outpatient

\section{Introduction}

As the prevalence of diabetes is increasing worldwide, the disease will take an increasing proportion of national healthcare budgets. The International Diabetes Federation (IDF) estimates that about 382 million people lived with diabetes mellitus (DM) as of 2013 and this figure is projected to rise to 592 million people in 2035 and majority, more than $90 \%$ have type $2 \mathrm{DM}$. There were 450,000 cases of diabetes in Ghana in 2014 and this figure is set to rise to 819,000 by 2035 at a prevalence of 3.4 per cent (IDF,2014).

Diabetes is a costly disease, not only for the affected individual and his/her family, but also for the health authorites. Studies in India estimate that for a low-income Indian family with an adult with diabetes, as much as $25 \%$ of family income may be devoted to diabetes care. For families in the USA with a child who has diabetes, the corresponding figure is $10 \%$ (WHO factsheet No 236, 2015).

A study on direct medical cost of type 2 diabetes in Singapore by Shuyu $\mathrm{Ng}$ et al(2015) found that the mean annual direct medical cost was $\$ 2,034$, of which $61 \%$ was accounted for by inpatient services, $35 \%$ by outpatient services and $4 \%$ by accident and emergency services. In this same study, the cost of DM treatments and diabetes withcomplications were found to be strong determinants of costs.

Data by IDF in 2003 shows that the top five countries with the highest costs of diabetes care in Sub-Saharan Africa are South Africa, Kenya, Zimbabwe, Nigeria and Ghana respectively.

The economic cost of diabetes and its complications is unaffordable by most sub-saharan Africans. Their incomes are insufficient to purchase anti-diabetic drugs, insulin and other supplies for management of their illness. It is estimated that direct medical costs of diabetes are 2-3 times higher than non-diabetic people (Esteghamati et al, 2009).

The medical cost of diabetes care is high for all income groups in Ghana. However, poor individuals in rural and urban areas experience chonic financial insecurities due to diabetes ( De-Graft Aikins, 2005). A study in Ghana by Yeboah, JA (2005) to assess the direct patient cost of managing type 2 DM at the Komfo Anokye Teaching Hospital, Ghana in 2005 estimated the annual cost per patient with type $2 \mathrm{DM}$ at 2,281,854 Ghana cedis with antidiabetic drugs making up 59.7\%, complication drugs $22.4 \%$ and also cost were higher among inpatients than the outpatients. Also from that study, transportation costs to and 


\section{International Journal of Science and Research (IJSR) \\ ISSN (Online): 2319-7064}

Index Copernicus Value (2013): 6.14 | Impact Factor (2015): 6.391

from patient residence and the hospital was $3.5 \%$ of total cost of expenditure.

Since type 2 DM accounts for approximately $90 \%$ of DM cases, knowing the cost associated with outpatient care of type $2 \mathrm{DM}$ is important for budget planning. The study therefore aim to estimate the annual direct medical costs of type 2 diabetes mellitus outpatient care in a Ghanaian Public Health System.

\section{Specific Objectives}

1) To estimate the mean annual direct medical cost per patient for the outpatient care of type $2 \mathrm{DM}$ patients at the Cape Coast Teaching Hospital.

2) To determine any correlation between total annual costs and duration of DM; individual demographic characteristics e.g. age, gender and type of treatments of DM.

3) To determine the cost of medications for co-morbid conditions like hypertension and dyslipidaemia.

\section{Methodology}

\section{Setting}

The study was conducted at the Cape Coast Teaching hospital(CCTH), Ghana. CCTH is a public hospital that provides inpatient and ambulatory care (primary care, specialist care services) and 24-hour emergency services.

\section{Study Population}

The study included patients who satisfy the following inclusion criteria: 1). Age $>30$ years at the time of diagnosis with diabetes 2). Being followed at the CCTH DM clinic for at least one year and 3) Consented to take part in the study. Exclusion criteria included having type $1 \mathrm{DM}$ and pregnant women with diabetes.

\section{Study Design}

The study was a cross-sectional prospective study using the bottom-up approach to estimate the different cost components. Direct medical costs were assessed for one year from $1^{\text {st }}$ January-31 ${ }^{\text {st }}$ December,2015. Direct medical costs included expenses with medications, diabetes-related laboratory investigations, cost of blood glucose strips, consultation fees and non-medical direct costs included expenses with diet products, artificial sweeteners, herbal products for diabetes management and transportation to and from patient's residence to clinic visits and for diabetesrelated laboratory investigations. The perspective for this study was that of the Public Healthcare System i.e National health insurance scheme.

\section{Sampling method/Data Collection}

Participants were randomly (every $3^{\text {rd }}$ client) selected during their review day at the clinic and a face to face interview conducted using a structured questionnaire. The questionnaire had six sections: section one was on demographics of participants which included age; sex; age at diagnosis with DM; duration of DM; highest educational level; occupation; and monthly household income. Section two included data on type of DM treatment and co-morbities .Data on direct medical costs were divided into four categories: Medications-antidiabetics (section three); diabetes-related laboratory tests (section Four); number of Consultations per year (section five); costs of transportation to and from clinic reviews, for laboratory testing and cost on artificial sweeteners or diet and herbal products (section six).

\section{Estimation of costs}

The total costs of outpatient diabetes care were assessed over the course of one (1) year, which was then converted into US dollars using an exchange rate as at May, 2016: US $\$ 1=3.82$ Ghana Cedis (GHS). Unit costs for physicians review, diabetes-related laboratory tests, medications for diabetes and co-morbidities were based on standardized rate using the 2015 National health insurance scheme(NHIS) medicine price list. Unit costs for diabetes-related laboratory tests not covered by NHIS were based on rate at the hospital, and data on medications not covered by NHIS and purchased from a private pharmacy were also obtained from the patients. Annual direct medical costs for consultations were estimated by multiplying the number of diabetes clinic visits for the year by the unit cost for each visit. The annual direct medical costs for medications were estimated by multiplying the quantity of each medication per month by the unit cost by the number of clinic visits for the year. The annual direct medical costs related to laboratory tests were assessed by multiplying the diabetes-related laboratory tests by the unit cost for each test for the year. Cost of transportation to and from patient residence for each clinic visits, for laboratory testing were estimated from the patient and multiplied by the number of clinic visits to get the annual transportation costs.

\section{Data Analysis}

Data were validated after entry and then analyzed using the Statistical Package for the Social Sciences version 21 (SPSS Inc, Chicago, IL, USA). Descriptive statistics (frequency, percentage, mean) were used for demographic information, clinical characteristics and cost variables.

\section{Ethical Approval}

Written permission was sought from the hospital management and informed consent was taken from individual study participants.

\section{Definitions}

\section{Direct cost}

Direct cost are costs for which payments are made and is further divided into direct medical and direct non- medical costs. Direct medical cost are cost of goods and services used in the diagnosis, treatment, rehabilitation and prevention of an illness or disorder in question. This include the costs of consultation, medications, investigations, hospitalization and glucose test strips. Direct non-medical cost is the cost of all other resources used related to the illness or disorder in question. This include costs of transportations for reviews, laboratory testing, woundcare and cost of herbal and diet products (Breslow,L 2002)

Direct medical costs in this study included expenses with:

- Medications (anti-diabetics, dyslipidemia drugs, and antihypertensives drugs).

- Diabetes-related laboratory testing

- Blood glucose strips (clinic plus home monitoring)

\section{Volume 5 Issue 6, June 2016 www.ijsr.net}




\section{International Journal of Science and Research (IJSR) \\ ISSN (Online): 2319-7064 \\ Index Copernicus Value (2013): 6.14 | Impact Factor (2015): 6.391}

- Consultation fees with physicians, nutritionists, dentist, ophthalmologist, woundcare.

\section{Direct non-medical cost}

In this study, direct non-medical cost included expenses with

- Diet products plus artificial sweeteners

- Transportation to attend clinic, for laboratory testing and for woundcare for diabetic ulcer if applicable.

- Cost of herbal products for diabetes management.

\section{Bottom-Up Approach}

This research approach starts from a selected subpopulation with the actual disease and all costs related to the disease are primarily gathered from the patient's records.

\section{Results}

Socio-demographic characteristicsof study participants From Table 1, a total of 204 patients were interviewed and majority were between the ages of $50-59$ years $(37.7 \%)$ and 60-69 years (31.9\%) respectively. Majority of the participants were females $(68.6 \%)$ and majority $(34.3 \%)$ had Middle School or Junior High School education followed by Senior High School (24.5\%). By occupation, majority $(33.1 \%)$ were retired, followed by self-employed $(22.1 \%)$ respectively. Of the total participants, majority $(33.3 \%)$ had mean monthly income of less than 200 Ghana Cedis (\$ 52.36 USD)

Table 1: Socio-demographic Characteristics of Study

\begin{tabular}{|c|c|c|}
\hline \multicolumn{3}{|c|}{ Participants } \\
\hline Variable & Number & Percentages \\
\hline Age (yrs): & & \\
\hline $30-39$ & 1 & 0.5 \\
\hline $40-49$ & 30 & 14.7 \\
\hline $50-59$ & 77 & 37.7 \\
\hline $60-69$ & 65 & 31.9 \\
\hline$>70$ & 31 & 15.2 \\
\hline Gender: & & \\
\hline Male & 64 & 31.4 \\
\hline Female & 140 & 68.6 \\
\hline Educational Level: & & \\
\hline None/Illiterate & 41 & 20.1 \\
\hline Primary & 12 & 5.9 \\
\hline Middle/JHS ${ }^{\mathrm{a}}$ & 70 & 34.3 \\
\hline SHS ${ }^{\mathrm{b}} /$ Vocational/Training College & 50 & 24.5 \\
\hline Tertiary/Polytechnic & 28 & 13.7 \\
\hline Postgraduate & 3 & 1.5 \\
\hline Occupation: & & \\
\hline Self-employed & 45 & 22.1 \\
\hline Fishmonger & 1 & 0.5 \\
\hline Farmer & 12 & 5.9 \\
\hline Civil/Public Servant & 39 & 19.1 \\
\hline Retired & 68 & 33.3 \\
\hline Others ${ }^{\mathrm{b}}$ & 39 & 19.1 \\
\hline Mean Monthly Income (GHS): & & \\
\hline$<200$ & 68 & 33.3 \\
\hline $200-499$ & 55 & 27.0 \\
\hline $500-799$ & 28 & 13.7 \\
\hline 800-1099 & 21 & 10.3 \\
\hline$>1100$ & 32 & 15.7 \\
\hline
\end{tabular}

a JHS=Junior High School ${ }^{\mathrm{b}} \mathrm{SHS}=$ Senior High School

b Others included: seamstress, commercial drivers, construction workers.
Clinical Characteristics of study participants

Majority $(43.1 \%)$ of the study participants have had the diabetes for between $1-5$ years with about $17.1 \%$ having it for more than 15 years. A larger proportion of the participants $163(79.9 \%)$ were on oral anti-diabetics, whiles $14(6.9 \%)$ and $25(12.3 \%)$ were treating their diabetes with insulin and insulin plus oral anti-diabetics respectively. Majority $(74.4 \%)$ of the participants had hypertension as a co-morbidity followed by dyslipidaemia (13.3\%). A larger proportion $(60.8 \%)$ did not own a glucometer whiles majority $(71.1 \%)$ of them also purchase medications from private pharmacy for management of their diabetes from out of pocket.

Table 2: Clinical Characteristics of Study Participants

\begin{tabular}{|l|c|c|}
\hline Variable & Number & Percentages \\
\hline Duration of Diabetes (yrs): & 13 & 6.4 \\
$<1$ & 88 & 43.1 \\
$1-5$ & 45 & 22.1 \\
$6-10$ & 23 & 11.3 \\
$11-15$ & 35 & 17.1 \\
$>15$ & & \\
& & \\
Type of Diabetes treatment: & 163 & 79.9 \\
Oral anti-diabetics & 14 & 6.9 \\
Insulin & 25 & 12.3 \\
Insulin + Orals & & \\
Co-morbidities: & 157 & 74.4 \\
Hypertension & 28 & 13.3 \\
Dyslipidaemia & 26 & 12.3 \\
Hypertension + Dyslipidaemia & & \\
Owns a Glucometer: & 80 & 39.2 \\
Yes & 124 & 60.8 \\
No & & \\
Buys Medications from Private & & \\
Pharmacy(Out of Pocket): & 145 & 71.1 \\
Yes & 59 & 28.9 \\
No & & \\
\hline
\end{tabular}

Table 3: Components of Annual Direct Medical Costs

\begin{tabular}{|c|c|c|}
\hline Variable & Number & $\begin{array}{c}\text { Mean Annual } \\
\text { Cost: GHS(US \$) }\end{array}$ \\
\hline Oral anti-diabetics & 162 & $636.75(166.69)^{\mathrm{a}}$ \\
Insulin & 14 & $774.00(202.62)$ \\
Insulin + Orals & 25 & $1026.34(268.68)$ \\
Diabetes-related laboratory & & $219.00(57.32)^{\mathrm{b}}$ \\
investigations & 204 & $247.41(64.77)^{\mathrm{c}}$ \\
Glucose strips & 58 & $200.00(52.36)^{\mathrm{d}}$ \\
Consultations & 204 & $188.29(49.29)^{\mathrm{e}}$ \\
Cost of medications bought & 145 & $1,491.45$ \\
from Private Pharmacies. & \multicolumn{3}{|c}{}
\end{tabular}

GHS ( US\$390.43) if on oral anti-diabetics 


\section{International Journal of Science and Research (IJSR) \\ ISSN (Online): 2319-7064}

Index Copernicus Value (2013): 6.14 | Impact Factor (2015): 6.391

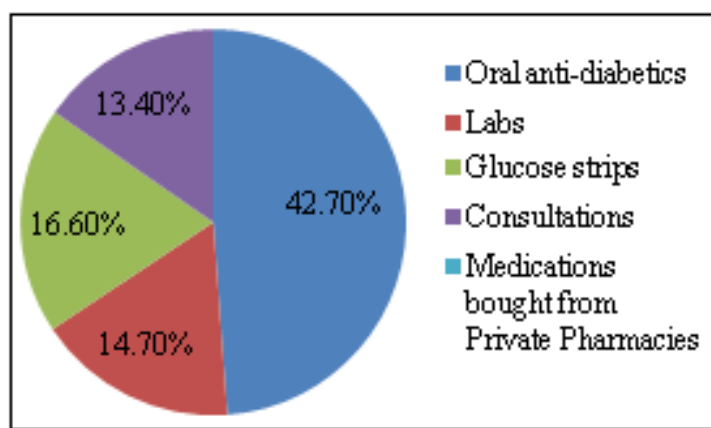

Figure 1: Percentage contributions of the components of direct medical costs

Table 4: Mean Annual Direct Medical cost of diabetes management in relation to demographic characteristics and duration of diabetes among studied Participants.

\begin{tabular}{|l|c|c|}
\hline \multicolumn{1}{|c|}{ Variable } & Number & $\begin{array}{c}\text { Mean Annual direct } \\
\text { medical cost }{ }^{\mathrm{a}} \text { : GHS } \\
\text { (US \$) }\end{array}$ \\
\hline $\begin{array}{l}\text { Age (yrs): } \\
<40\end{array}$ & 1 & $1470.20(384.87)$ \\
$40-49$ & 30 & $1496.00(391.62)$ \\
$50-59$ & 77 & $1335.50(349.48)$ \\
$60-69$ & 65 & $1357.22(355.29)$ \\
$>70$ & 31 & $1236.44(323.29)$ \\
Gender: & 64 & $1270.47(332.58)$ \\
Male & 140 & $1386.58(362.98)$ \\
Female & & \\
Duration of Diabetes (yrs): & 13 & $1290.60(337.85)$ \\
$<1$ & 88 & $1278.82(334.77)$ \\
$1-5$ & 45 & $1305.23(341.68)$ \\
$6-10$ & 23 & $1440.00(376.96)$ \\
$11-15$ & 35 & $1557.87(407.82)$ \\
\hline 15 & &
\end{tabular}

Cost was calculated using oral anti-diabetics and the various components of direct medical costs.

Table 5: Mean Annual Medication costs for co-morbid conditions among study Participants.

\begin{tabular}{|c|c|c|}
\hline Co-morbidit & Number & $\begin{array}{c}\text { Mean Annual Medication } \\
\text { Costs: GHS (US \$) }\end{array}$ \\
\hline Hypertension & 157 & $469.94(123.02)$ \\
Dyslipidaemia & 28 & $344.42(90.16)$ \\
\hline
\end{tabular}

\section{Direct medical cost of diabetes care}

The total mean annual direct medical cost for the outpatient management of type 2 diabetes mellitus at the Cape Coast teaching hospital came to 1,491.45 GHS (US\$ 390.43) (Table 3). The mean annual cost for oral anti-diabetics, insulin and insulin plus oral anti-diabetics were US\$166.69, \$202.62 and \$268.68 USD respectively. That of diabetesrelated laboratory investigations, glucose strips, consultation fees and medications bought from private pharmacy came to US\$57.32, \$64.77, \$52.36 and \$49.29 respectively.

From figure 1, the cost for medicines represent the largest proportion $(42.7 \%)$ of direct medical cost, followed by the cost of glucose strips $(16.6 \%)$ and laboratory investigations $(14.7 \%)$ respectively.

Table 4 shows that the mean annual direct medical cost of diabetes management were higher for females compared to males (US\$362.98 vs. \$332.58). Considering age, the mean annual direct medical cost was higher amongst the 40-49 age group compared to older age groups. Also the mean annual direct medical cost for participants whose duration of diabetes was <1 year was US $\$ 337.85$; between $1-5$ years was (US \$334.77); 6-10 years was (US\$341.68); 11-15 years was (US\$376.96) and >15 years was (US\$407.82) respectively.

Table 5 shows the mean annual medication costs for those with co-morbid conditions which is an additional cost to what they spend for diabetes management. It shows that having co-morbid conditions like hypertension and dyslipidaemia will cost an additional US\$123.02 and \$90.16 annually respectively on medications.

Table 6: Mean Annual Direct Non-Medical Cost.

\begin{tabular}{|l|l|l|}
\hline Variable & Number & $\begin{array}{l}\text { Mean Annual } \\
\text { Direct non- } \\
\text { medical cost: } \\
\text { GHS (US\$) }\end{array}$ \\
\hline Transportation (to and from clinic). & 195 & $58.05(15.20)$ \\
Artificial Sweeteners & 52 & $29.43(7.70)$ \\
Herbal medications & 11 & $23.45(6.14)$ \\
\hline
\end{tabular}

\section{Direct non-medical cost}

From Table 6, the mean annual cost for patient transportation for attending consultations and for laboratory investigations; for buying artificial sweeteners and herbal medicines for diabetes management was US \$15.20; $\$ 7.70$ and $\$ 6.14$ respectively.

\section{Discussion}

Diabetes is a costly disease to manage and its cost affects individuals, families, healthcare systems and national productivity. This study identifies the components of direct medical cost and the magnitude of the contribution of each component. Studies on the total cost of diabetes in Africa are few and of the cost analyses undertaken, different techniques have been used, making comparison difficult.

This study showed that the mean annual direct medical cost for outpatient diabetes care was US $\$ 390.43$ when on oral anti-diabetics, the largest component of which was attributed to medications $(42.7 \%)$, followed by glucose strips (16.6\%) and diabetes-related laboratory investigations (14.7\%) respectively. A study conducted in Iran by Davari et al (2016) to assess the direct medical costs of outpatient cases of type 2 diabetes showed that pharmaceutical expenditures was the main cost component of outpatient cases for diabetes followed by laboratory tests. This study also showed that the mean annual direct medical cost is higher in participants with diabetes of longer duration (>15 years), findings which compares to other studies (Grover et al; Shobhana et al; Rayappa et al ).

This study also showed that the mean annual cost is higher when on insulin or on insulin plus oral antidiabetics. Study by Brandle et al (2003) in the USA found that insulin treatment were associated with $60-90 \%$ increases in direct medical cost of type 2 diabetes mellitus. Another study carried out in Sweden to assess the direct medical costs for patients with type 2 diabetes in Sweden by Henriksson et al (2000) found that costs increased with diabetes duration and

\section{Volume 5 Issue 6, June 2016 www.ijsr.net}




\section{International Journal of Science and Research (IJSR) \\ ISSN (Online): 2319-7064 \\ Index Copernicus Value (2013): 6.14 | Impact Factor (2015): 6.391}

were higher for patients treated with insulin compared to those treated with oral hypoglycaemic drugs.

In this study, majority $(71.1 \%)$ of the patients used out of pocket money to buy medications from private pharmacy which averages US\$ 49.29 annually. This amount was spent on medications that were not available at the hospital pharmacy during their review. This study also showed that the mean annual direct medical cost on the average was higher in females than males (US\$ 362.98 vs. \$332.58). A study conducted in America showed that the total direct costs of therapeutic regimen for a diabetic woman were almost 24\% higher than a diabetic man (Brandle et al, 2003).

The study also showed that having an additional comorbidity will escalate the cost of managing diabetes. Having hypertension or dyslipidaemia as a co-morbidity means spending an additional US\$ 123.02 and US\$ 90.16 annually respectively. The mean annual direct non-medical cost was 110.93 GHS (US\$29.04), of which patient transportation costs for attending consultations and or/ undergoing laboratory investigations was US\$ 15.20 annually. The study also showed that majority of the participants $(60.8 \%)$ did not own glucometer as a result of financial difficulties. Also it is interesting to note that in a country where there is high usage of herbal medications, only 11 out of the 204 participants spent money to buy herbal medications for the treatment of their diabetes. The reason for the low number may be due to the diabetes educations that clients receive at the clinic during their reviews.

The findings of our study suggest that there is an imperative need to develop and improve interventions toward prevention of diabetes, co-morbities and its complications. There is a need to promote more research at a national level on diabetes based economic studies to know the social, financial and economic burden of diabetes in order to inform policy.

\section{References}

[1] American Diabetes Association. Economic costs of diabetes in the U.S. in 2012. Diabetes Care, 36 (2013), pp 1033-146.

[2] Brandle,M; Zhou,H., Smith, B.R.K., Marriott, D., Burke, R., Tabaei, B.P., Brown, M.B., Herman, W.H (2003). The Direct Medical Cost of Type 2 diabetes. Diabetes Care, 26 (8), 2300-4

[3] Breslow, L.(Ed).(2002). Encyclopedia of Public Health: SZ (Vol.4). Macmillan Reference library.

[4] Davari M., Boroumand, Z., Amini M., Aslani A., Hosseini M. (2016) The direct medical costs of outpatient care of Type 2 diabetes in Iran: A retrospective Study. Int J Prev Med 2016; 7:72.

[5] De-graft Aikins, A. (2005) Healer-shopping in Africa: new evidence from a rural-urban qualitative study of Ghanaian diabetes experiences. British Medical Journal, 331, 737

[6] Esteghamati A, Khalilzadah O, Anvari M, Meysamie A, Abbasi M, Forouzanfar M, Alaeddini F (2009). The economic costs of diabetes: a population-based study in Tehran, Iran. Diabetologia, 52:1520-1527
[7] Grover S, Avasthi A, Bhansali A, Chakrabarti S, Kulhara P: Cost of ambulatory care of diabetes mellitus: a study from north India. Postgrad Med J 2005, 81 (956): 391-395

[8] Henriksson,F., Agardh,C.D.,Berne,C., Bolinder, J., Lonnqvist, F., Stenstrom,P., Ostenson,C,G., Jonsson, B.(2000) Direct medical costs for patients with type 2 diabetes in Sweden. Journal of Internal Medicine, vol 248, issue 5, pp387-396.

[9] International Diabetes Federation: Diabetes Atlas 2014

[10] Rayappa PH, Raju KNM, Kapur A, Bjork S, Sylvest C, Dilip Kumar KM: Economic Cost of Diabetes care. The Bangalore Urban District Diabetes Study. Int J Diab 1999, 19:87-97.

[11] Shobhana R, Rama Rao P, Lavanya A, Williams R, Padma C, Vijay V, Ramachandran A: Costs incurred by families having Type 1 diabetes in a developing country-a study from southern India. Diabetes Res Clin Pract 2002, 55 (I): 45-48.

[12] Shuyu Ng, C., Toh, M.P.H.S., Ko, Y., Yu-Chia Lee, J. (2015) Direct medical cost of type 2 diabetes in Singapore. Plosone, 10(3)

[13] WHO factsheet No. 236 (2015). The cost of Diabetes.

[14] Yeboah, J.A.(2005) Assessment of direct patient cost of managing diabetes mellitus at the Komfo Anokye Teaching Hospital, Kumasi. A dissertation presented to the school of Graduate studies Kwame Nkrumah University of Science and Technology.

\section{Author Profile}

Immanuel Amissah was the principal author and contributed to the study concept, design and interpretation and discussion of data.JDD contributed to the data collection and analysis of the data. 